\title{
Stochastic simulation using a Risk for dairy business investment decisions
}

\author{
J.M. Bewley, M.D. Boehlje, A.W. Gray, H. Hogeveen, S.J. Kenyon, \\ S.D. Eicher, and M.M. Schutz \\ (Information about the authors can be found at the end of the paper)
}

\section{Dairy business investment decisions}

\begin{abstract}
Purpose - The purpose of this paper is to develop a dynamic, stochastic, mechanistic simulation model of a dairy business to evaluate the cost and benefit streams coinciding with technology investments. The model was constructed to embody the biological and economical complexities of a dairy farm system within a partial budgeting framework. A primary objective was to establish a flexible, user-friendly, farm-specific, decision-making tool for dairy producers or their advisers and technology manufacturers.

Design/methodology/approach - The basic deterministic model was created in Microsoft Excel (Microsoft, Seattle, Washington). The @Risk add-in (Palisade Corporation, Ithaca, New York) for Excel was employed to account for the stochastic nature of key variables within a Monte Carlo simulation. Net present value was the primary metric used to assess the economic profitability of investments. The model was composed of a series of modules, which synergistically provide the necessary inputs for profitability analysis. Estimates of biological relationships within the model were obtained from the literature in an attempt to represent an average or typical US dairy. Technology benefits were appraised from the resulting impact on disease incidence, disease impact, and reproductive performance. In this paper, the model structure and methodology were described in detail.

Findings - Examples of the utility of examining the influence of stochastic input and output prices on the costs of culling, days open, and disease were examined. Each of these parameters was highly sensitive to stochastic prices and deterministic inputs.

Originality/value - Decision support tools, such as this one, that are designed to investigate dairy business decisions may benefit dairy producers.

Keywords Investment appraisal, Net present value, Agriculture, Stochastic processes, Modelling Paper type Research paper
\end{abstract}

\section{Introduction}

Dairy managers must consider both biological and economic considerations simultaneously in their decisions. Traditionally, investment decisions have been made using standard recommendations, rules of thumb, consultant advice, or intuition. Thus, more objective methods of investment analysis are needed (Verstegen et al., 1995). Today's dairy manager is presented with a constant stream of new technologies to consider including new "precision dairy farming" (PDF) technologies. PDF has been described as the use of technology to collect data from individual animals (Spilke and Fahr, 2003). Perceived benefits of PDF technologies include increased efficiency, improved quality, minimized detrimental environmental impacts, increased fertility, ameliorated disease effects, and

The authors would like to express gratitude to the following individuals for their assistance on methodology for specific parts of this model: Huybert Groenendaal, Nicolas Friggens, Paivi Rajala-Schultz, Patrick French, Gregg Hadley, and Robert Boyce.

No copyright is associated with this paper because of the author's employment by the United States Federal Government at the time the paper was written.
Agricultural Finance Review Vol. 70 No. 1,2010 pp. $97-125$ Emerald Group Publishing Limited 0002-1466

DOI $10.1108 / 00021461011042666$ 
AFR 70,1

more systematically produced, biologically based, specific-attribute raw materials (Boehlje et al., 1999; de Mol, 2000). Nevertheless, adoption of these technologies in the dairy industry has been sparse (Eleveld et al., 1992; Huirne et al., 1997a; Gelb et al., 2001).

Investment analyses of information systems and technologies are common within the general business literature (Streeter and Hornbaker, 1993; Ryan and Harrison, 2000; Lee and Bose, 2002). Additionally, examples of investment models for other agricultural enterprises exist (Odening et al., 2005; Seavert et al., 2006). However, dairyspecific tools examining investment of PDF technologies are limited (Carmi, 1992; Gelb, 1996; van Asseldonk, 1999), though investment analyses of other dairy technologies abound (Hyde and Engel, 2002; Hyde et al., 2003). Empirical comparisons of technology before or after adoption or between herds that have adopted a technology and control herds that have not adopted are expensive and biased by other, possibly herd-related differences. As a result, the normative approach, using simulation modeling, predominates in decision support models in animal agriculture (Dijkhuizen et al., 1991).

Investing in new agricultural technologies is all too often a daunting and complex task. First, the standard approach using the net present value (NPV) is often misleading because it does not adequately account for underlying uncertainties. Second, the incremental costs and benefits of new technologies require complex interactions of multiple variables that are often non-linear and not intuitive. The complexities surrounding investment in PDF technologies is one example. In this paper, we develop a systematic approach for investigating PDF investment decisions and demonstrate that this exercise requires interactions of many biological and physiological parameters. Our approach addresses many issues that have been a hindrance to this type of analyses. For example, enumerating the risk of response to technology investment is difficult especially if the technology has no history from which to enumerate probabilities. Management must rely on expert opinion as a firstbest guess of what these risks would be. The purpose of this paper is to describe a dynamic simulation model developed for examination of the economics of technology adoption on dairy farms considering both economic and biological factors.

\section{Materials and methods \\ Model overview}

A dynamic, stochastic, mechanistic simulation model of a dairy enterprise was developed to evaluate the economics of investments in technologies. The model was designed to characterize the biological and economical complexities of a dairy system within a partial budgeting framework by examining the cost and benefit streams coinciding with investment in a PDF technology. A secondary aim was to develop the model in a manner conducive to future utility as a flexible, farm-specific decisionmaking tool. The basic deterministic model was constructed in Microsoft Excel 2007 (Microsoft, Seattle, Washington). The @Risk 5.0 (Palisade Corporation, Ithaca, New York) add-in for Excel was utilized to account for the stochastic nature of key variables in the Monte Carlo simulation.

\section{Model structure}

The modeling process began by defining a series of inputs to describe the initial status and behavior of the farm system. The underlying behavior of the dairy system was represented using current knowledge of herd and cow management with relationships defined from existing literature. Historical prices for critical sources of revenues and expenses within the system were also incorporated as model inputs. Detailed 
descriptions of system behavior and calculation of prices are included in subsequent sections.

The flexibility of this model lies in the ability to change inputs describing the initial herd characteristics and the potential impact of the technology. In many cases, farm managers or advisors may not know or have access to all input variables. As an alternative to entering herd-specific values, the user may choose to keep some or all variables at the default values provided in the model. For research example applications, industry averages, selected to represent conditions on US dairy farms in 2007 were incorporated into analyses as defaults (Tables I and II). Inputs for potential improvements in animal productivity, health, or reproduction resulting from technology adoption were used to estimate alternative scenarios with or without the technology.

After these inputs were entered into the model, an extensive series of intermediate calculations was computed within 13 modules. Each module tracked changes over a ten-year period for its respective variables. Within these inter-connected modules, the impact of inputs, stochastic variables, and technology-induced improvements were estimated over time using the underlying system behavior within the model. Results of calculations within one module often affected calculations in other modules with multiple feed-forward and feed-backward interdependencies. Each of these modules eventually resulted in a calculation that would influence the cost and revenue flows necessary for the partial budget analysis. Finally, the costs and revenues were utilized for the project analysis examining the NPV and financial feasibility of the project along with associated sensitivity analyses.

\section{Stochastic prices module}

Agricultural commodity markets are characterized by tremendous volatility. As a result, economic conditions and the profitability of investments can vary considerably depending on the prices paid for inputs and the prices received for outputs. Dairy managers are often critical of economic analyses that fail to account for this volatility, by using a single value for critical prices, recognizing that the results of the analysis may be different with higher or lower milk prices, for example. In a simulation model, variability in prices can be accounted for by modeling these variables stochastically.

Historical US prices from 1971 to 2006 for milk, replacement heifers, alfalfa, corn, and soybeans were collected from the "Understanding Dairy Markets" website (Gould, 2007). Historical cull cow prices were defined using the USDA-National Agricultural Statistics Service values for "beef cows and cull dairy cows sold for slaughter" (USDANASS, 2007). Base values for future prices (2007-2016) of milk, corn, soybeans, alfalfa, and cull cows were set using estimates from the Food and Agricultural Policy Research Institute's (FAPRI) USA and World Agricultural Outlook Report (FAPRI, 2007). Because FAPRI does not provide estimates of future prices for replacement heifers, a regression equation $\left(R^{2}=0.89\right)$ was computed to estimate future replacement heifer prices as follows, although other researchers in different situations may use different relationships:

$$
\mathrm{REPP}=-49026.4+652.41 \times \mathrm{CULLP}+24.90 \times \mathrm{YR},
$$

where REPP is replacement heifer price (\$/head), CULLP is cull cow price $(\$ / \mathrm{kg})$, and YR is a counter for year starting with 1971 as year 1 .

Dairy business investment decisions 


\begin{tabular}{|c|c|c|c|}
\hline & & & \\
\hline $\mathrm{AFR}$ & Parameter & Value & Reference \\
\hline & Number of milking cows & 1,000 & Model input \\
\hline & Capacity of milking herd facilities, number cows & 1,000 & Model input \\
\hline & Overcrowding threshold, $\%$ above facility capacity & 0.00 & Model input \\
\hline & Heifers, $0-12$ months as a percentage of total herd & 39.60 & DairyMetrics \\
\hline & Heifers, $>12$ months as a percentage of total herd & 37.80 & DairyMetrics \\
\hline 100 & Percentage of herd in 1st lactation & 36.10 & Dhuyvetter et al. (2007) \\
\hline & Percentage of herd in 2nd lactation & 26.00 & Dhuyvetter et al. (2007) \\
\hline & Percentage of herd in 3rd lactation & 17.70 & Dhuyvetter et al. (2007) \\
\hline & Percentage of herd in 4th lactation & 11.00 & Dhuyvetter et al. (2007) \\
\hline & Percentage of herd in 5th lactation & 5.80 & Dhuyvetter et al. (2007) \\
\hline & Percentage of herd in $\geq 6$ th lactation & 3.40 & Dhuyvetter et al. (2007) \\
\hline & DIM designated do not breed & 300 & Model input \\
\hline & Cull milk yield, kg per day & 15.88 & Model input \\
\hline & Mature cow live body weight, $\mathrm{kg}$ & 723.48 & NRC $(2001)^{\mathrm{a}}$ \\
\hline & Slaughter cow body weight, $\mathrm{kg}$ & 623.69 & Dhuyvetter et al. (2007) \\
\hline & Calf birth body weight, $\mathrm{kg}$ & 41.73 & Kertz et al. (1997) \\
\hline & Voluntary waiting period, days & 58.4 & DairyMetrics \\
\hline & Gestation length, days & 280.00 & Norman et al. (2007) \\
\hline & $\begin{array}{l}\text { Baseline culling rate for } 1 \text { st parity, all culls (\%) } \\
\text { other than modeled diseases }(\%)\end{array}$ & 13.00 & Model input \\
\hline & Percentage of heifer calves & 46.60 & Silva de Rio et al. (2005) \\
\hline & Perinatal calf mortality, $<48$ hours (\%) & 6.50 & NAHMS (2007) \\
\hline & Unweaned heifer death rate $(\%)$ & 6.50 & NAHMS (2007) \\
\hline & Weaned heifer death rate $(\%)$ & 1.80 & NAHMS (2007) \\
\hline & Age at first calving, months & 24.0 & NAHMS (2007) \\
\hline & Twinning rate $(\%)$ & 4.10 & Silva de Rio et al. (2005) \\
\hline & Days dry & 59.6 & NAHMS (2007) \\
\hline & Initial RHA, kg & $10,903.20$ & DairyMetrics \\
\hline & $\%$ Annual production increase & 1.52 & $\begin{array}{l}\text { Genetic and phenotypic } \\
\text { trends, USDA-AIPL (2006) }\end{array}$ \\
\hline & Heat detection rate $(\%)$ & 54.50 & DairyMetrics \\
\hline & Conception rate $(\%)$ & 30.10 & DairyMetrics \\
\hline & Butterfat (\%) & 3.70 & DairyMetrics \\
\hline & Protein $(\%)$, true & 3.10 & DairyMetrics \\
\hline & Time of target BCS in DIM & 112.00 & Friggens et al. (2004) \\
\hline
\end{tabular}

Table I.

Default inputs for herd parameters
Notes: Model inputs are reasonable values for inputs selected within ranges observed from the authors' experience; Holstein herds with at least 500 cows; USDA National Animal Health Monitoring System (NAHMS) (2007) values for large (500 cows or more) herds; ${ }^{a}$ Mid-point between typical and large Holstein

Source: Dairy Metrics (2008)

The following technique was utilized to forecast stochastic prices for milk, replacement heifers, cull cows, alfalfa, corn, and soybeans. First, annual prices were converted to a logarithmic scale (LOGP). Then, regression equations for each commodity price were developed to predict LOGP using LOGP from the preceding year and a year counter, with 1971 as year 1 . The predicted LOGP were converted back to a standard price in dollars. Next, residual terms were calculated by dividing the difference between the actual and predicted prices by the predicted price. These residual terms were sorted from smallest to largest and pseudo minimum and pseudo maximum residual terms were calculated by multiplying the smallest and largest residual terms, respectively, by 1.0001 . 


\begin{tabular}{|c|c|c|c|}
\hline Parameter & Value & Reference & \multirow{3}{*}{$\begin{array}{l}\text { Dairy business } \\
\text { investment } \\
\text { decisions }\end{array}$} \\
\hline Annual discount rate (\%) & 8.00 & Hyde and Engel (2002) & \\
\hline Interest rate $(\%)$ & 7.20 & Smith (MS, 2007, personal communication) & \\
\hline Tax rate $(\%)$ & 35.00 & Boehlje (MB, 2005, personal communication) & \multirow{4}{*}{101} \\
\hline Inflation rate for labor (\%) & $2-5^{\mathrm{a}}$ & Hyde and Engel (2002) & \\
\hline Labor cost, $\$$ per hour & 20.00 & Hutjens and Aalseth (2005) & \\
\hline Heifer calf value (\$) & 400 & Dhuyvetter et al. (2007) & \\
\hline Bull calf value $(\$)$ & 100 & Dhuyvetter et al. (2007) & \\
\hline Semen costs, per straw $(\$)$ & 15.00 & De Vries (2004) & \\
\hline Yearly veterinary costs, 1st parity $(\$)$ & $70^{\mathrm{b}}$ & Groenendaal et al. (2004) & \\
\hline Cull cow price adjustment (\%) & $10.00^{\mathrm{c}}$ & Dhuyvetter et al. (2007) & \\
\hline Dry cow feed price, $\$ / \mathrm{kg}$ DMI & 0.15 & Model input & \\
\hline Financial losses at disposal (\$) & 50 & Groenendaal et al. (2004) & \\
\hline \multicolumn{3}{|c|}{$\begin{array}{l}\text { Notes: Used in RPO module to account for foregone genetic improvement; }{ }^{\text {a }} \text { modeled } \\
\text { stochastically as a uniform distribution; badjusted for inflation to 2,006 dollars; ' }{ }^{\text {adjustment }} \\
\text { accounting for cull cows generally being thin at culling }\end{array}$} & $\begin{array}{r}\text { Table II. } \\
\text { Default inputs for } \\
\text { financial parameters } \\
\text { across years }\end{array}$ \\
\hline
\end{tabular}

An assumption was made that the probability of observing each of the residual terms was equal. In turn, the sorted residual terms and their associated cumulative probabilities were incorporated into empirical distributions, using the RiskCumul function of @Risk. These empirical distributions were used to estimate error terms to account for potential variation in prices from expected prices. The deterministic expected price for a given year was set using the FAPRI estimates for each commodity. Finally, the simulated error terms were added to the deterministic prices to provide stochastic commodity prices. A correlation matrix of the six simulated commodity prices was incorporated in the simulations to account for correlations among commodity prices within a given year in each simulation. This calculation was essential in order to avoid simulating unrealistic scenarios for combined prices, each drawn from historical distributions, within a given year (e.g. elevated corn prices and depressed soybean prices). Calculating prices in this manner assumed that the production of the individual farm had no impact on the prices that they pay or receive.

\section{Stochastic variables module}

In this module, most stochastic variables within the model were either collected or calculated, including the stochastic prices already mentioned and stochastic variables related to technology adoption. In addition, the overall feed costs were calculated using the formula described by Bailey and Ishler (2007) which represents the cost of a typical 16 percent protein mixed feed. The stochastic prices were transferred to the other disease costs, disease milk loss, reproduction, and revenues and expenses modules. Other stochastic variables within this module were used in the body condition score (BCS), reproduction, disease milk loss, culling, and other disease costs modules.

\section{Herd demographics module}

The Herd demographics module portrayed the annual flow of animals in the herd across ten years, along with predicted milk production trends. This module was based largely on the work of St-Pierre (1999). The initial herd was established using either the farm-specific values or model defaults defined as inputs. An important assumption in this module was that cows were evenly distributed throughout the herd by stage of 
AFR 70,1

lactation (e.g. no seasonal calving periods). Calvings were assumed to be evenly distributed throughout the year. For example, if there were 365 cows in the herd with a 12-month calving interval, one calf would be born each day of the year and the distribution of lactation stages would follow accordingly. The distribution of cows within the lactation was adjusted according to the calving intervals calculated each year in the reproduction module. Cows were divided into six parity categories (1-5 and $\geq 6$ ) and distributed by parity within the following lactation stage categories: $\leq 21$ days in milk (DIM), 22-100 DIM, 101 DIM-dry, far-off dry, and close-up dry.

Another important assumption within this module was that the herd was at a steady state with no intentions of expansion within the decision period. In this type of dynamic model, without proper constraints, the herd size may increase or decrease rapidly depending on the culling rates. Within simulation models, a common strategy implemented to control herd size has been to use a maximum and minimum number of cows to determine when there was a need for selling excess cows or purchasing cows needed to maintain herd size (Sorensen et al., 1992). To manage this concern, at the end of each year, the total milking herd size was compared to the capacity of milking herd facilities and the tolerable level of overcrowding indicated in the inputs. If the number of milking cows exceeded the maximum desirable milking herd size, replacement heifers were sold beginning with springing heifers and continuing with younger animals as needed. Similarly, if the size of the milking herd at the end of a year decreased below the capacity of the milking herd facilities, replacement heifers were purchased to maintain herd size. Because excesses or deficits in heifer availability are more likely to be a factor of overall herd culling rates with only a small influence from the PDF technology being evaluated, the value of these liquidated or purchased replacement heifers was not accounted for in the partial budgeting revenues.

The number and percentage of culls during the year were calculated by parity within the culling module. Culls were distributed equally throughout the year. For new first parity cows entering the herd during the year, the culling rate was adjusted by month of calving. For example, the culling rates for first parity cows calving in January, June, and December were $1,1 / 2$, and $1 / 12$, of the overall first parity culling rate, respectively. For first parity cows already in the herd at the beginning of the year, the full culling rate was applied. The fate of existing cows within the herd was dependent on the calving intervals and culling rates during a year. A cow in the herd at the beginning of a year had three possible fates at the end of that year; she was culled from the herd, she completed her current lactation and began a new lactation, or she continued the current lactation into the next year. The sum of the number of cows transitioning to a new lactation and the number of replacement heifers calving, given existing heifer populations and age at first calving, equaled the number of calvings within a given year.

The number of live heifer calves born in a year was calculated with the following equation:

$$
\mathrm{LHC}=(((\mathrm{CPY} \times \mathrm{HCP}) \times(1-\mathrm{TR})+(\mathrm{CPY} \times \mathrm{TR} \times 0.25 \times 2))) \times(1-\mathrm{DOA}),
$$

where LHC is the number of live heifer calves born in a year, CPY is the number of calvings per year, HCP is the percentage of heifer calves, TR is the twinning rate, and DOA is the percentage of calves born dead or that die in the first 48 hours of life.

During the first two years of the simulation, the number of replacement heifers entering the herd depended largely on the number of heifers in inventory entered as 
inputs. In subsequent years, the number of heifers in the herd, which were separated into two categories (0-12 months and 12 months to first calving) was calculated based on live heifer calves born in the herd taking into account heifer culls and deaths until first calving along with predicted age at first calving. Calving interval has a direct impact on number of calves born and, subsequently, number of replacement heifers available (Skidmore, 1990).

The rolling herd average (RHA) milk production for the herd in the first year of the simulation was a model input. For subsequent years, RHA was adjusted annually based upon the phenotypic trend for annual increases in milk production. The yearly average milk production and dry matter intake (DMI) per cow were calculated as parity-weighted averages of the average cow simulated in the average cow simulation module. Values calculated in the herd demographics module were transferred into the average cow simulation, BCS, culling, disease milk loss, revenues and expenses, and reproduction modules.

\section{Average cow simulation module}

With decisions in investments made at the herd level rather than the animal level, this model was built without variation between cows. Humphry et al. (2005) compared two stochastic models of a bovine viral diarrhea outbreak in a beef herd. The only major difference between these two models was that one was a herd-based spreadsheet model and the other was an individual animal-based model. Because of the familiarity with the user-interface and the ability to discern easily how changes in key variables affect model output, end-users tended to be more accepting of the herd-based model. Considering that an individual animal-based model, although robust, will never provide perfectly precise outputs due to data limitations, the practicality and ease of use of the herd-based model may be preferred. These authors concluded that the individual animal-based model was more appropriate for research because it was more structurally accurate and that the herd-based model was more appropriate for helping producers make decisions. Perhaps more importantly, the current model was computationally demanding. Modeling individual animals would increase the time needed to run a simulation exponentially, reducing the applicability of the model for on-farm decision making.

A series of biological and economic parameters were calculated on a daily basis for the average or typical cow in the herd during each of the ten years of the simulation. As the cow progressed in age, transitions between biological states were made according to averages for age at first calving, calving interval, length of dry period, and DIM at conception. In this module, complete lactations were calculated for six parities. The parameters calculated for sixth parity animals were used to represent values for seventh to 12 th parities. Calculations from this module flow into the BCS, herd demographics, and retention pay-off modules. Beginning with the first day of the first lactation, the following parameters were calculated for the average cow on a daily basis.

Daily milk yield and DMI. Daily milk yield was calculated using the lactation curve developed by Oltenacu et al. (1981) with modifications by Marsh et al. (1988) and Skidmore. DMI was calculated using National Research Council (NRC) (2001) equations.

Revenues. Daily revenues from milk were entered into the retention pay-off module. For simplification, because of the complexities of varying cow longevity and the dynamics of future revenues among cows, the deterministic milk price for each respective year was utilized in milk revenue calculations rather than the stochastic

\section{Dairy business investment decisions}


AFR 70,1

milk price. The price was converted to $\$$ per $\mathrm{kg}$ and multiplied by daily milk production to calculate daily revenues from milk production. Revenues from the birth of a calf were recognized on the first day of a new lactation and calculated with the methodology described by Dhuyvetter et al. (2007) with an additional consideration of twinning rate.

Costs. The deterministic lactating cow feed price for a given year from the prices module was converted to a per kg dry matter basis assuming 60 percent ration dry matter. Then, this new price was multiplied by daily DMI to calculate daily lactating cow feed costs. Dry cow feed costs were calculated in a similar manner except that dry cow ration cost per kg of DMI was a constant from the inputs. Daily breeding costs were calculated with the methodology described by Groenendaal et al. (2004). This equation calculated an estimated cost per day for semen by distributing the semen costs per pregnancy evenly through the eligible breeding period for the respective cow.

\section{BCS module}

Body condition score. During early lactation, most dairy cows rely heavily on body energy reserves to meet the nutritional demands of milk production. The primary method of assessing body energy reserves of dairy cows is a subjective analysis of body energy content, termed body condition scoring. In the USA, this scoring is conducted subjectively and visually with a 1 (thin) to 5 (fat) scale at 0.25 point intervals (Ferguson et al., 1994). The patterns of BCS change and the associated exchange of energy within lactation play a critical role in dairy cow health, productivity, and efficiency. In this module, predicted daily changes in BCS were modeled using average $\mathrm{BCS}$ at calving (BCSC) as the primary model input. The percentage of cows calving within the following ranges was used to calculate a weighted average BCSC: 1.00-1.75, 2.00-2.25, 2.50-2.75, 3.00-3.25, 3.50-3.75, 4.00-4.25, and 4.50-5.00. Within each range, cows were distributed equally among possible scores.

All cows have a genetically programmed target BCS that they will attempt to attain at ten to 12 weeks post-calving (BCSTAR) (Friggens et al., 2004; Garnsworthy, 2007). For a cow that begins lactation above this target, intake is reduced and energy reserves are decreased. Conversely, a cow that begins lactation below this target will actually increase intake resulting in increased condition during early lactation. Using the equation described by Garnsworthy (2007), the change in BCS during early lactation $(\mathrm{BCS} \Delta)$ for respective $\mathrm{BCSC}$ on the UK scale were calculated. Then, these scores were converted to the US BCS scale using the conversion equation described by Bewley et al. (2010) for conversion of scores from the UK BCS (Lowman $e$ t al., 1976) system to the US BCS (Ferguson et al., 1994) system. Finally, these calculated scores were rounded to the nearest quarter point and used to predict $\mathrm{BCS} \Delta$ and BCSTAR for each point on the US BCS scale.

Using the percentage of cows calving in the BCS ranges, defined earlier, weighted averages of BCS $\Delta$ and BCSTAR were calculated. Ultimately, the average cow in the herd during each year of the simulation was assumed to begin each lactation at the weighted average BCSC, decrease BCS until she reaches BCSTAR, and increase BCS until the beginning of the subsequent lactation. Again, using the herd-based average cow model structure, an assumption was made that, at a herd level, the higher BCS loss by extremely fat cows was negated by the BCS gain by extremely thin cows. These daily changes in BCS were calculated using the methodology described by Friggens et al. (2004) for body lipid change. A Gompertz growth model was used to describe changes in body weight associated with growth toward maturity (Skidmore, 1990). 
The ADG in body weight from growth of the gravid uterus during pregnancy was calculated using the methodology described by Fox et al. (1999).

Daily body weight. Lastly, daily body weight was calculated as a function of the change in body weight from growth, conceptus (embryo and associated membranes) growth or removal, and daily BCS change. The total cumulative conceptus weight was subtracted from daily body weight on the day of calving. The change in body weight from change in BCS was calculated with the assumption that the mean change in body weight per one-unit change in BCS was 13.7 percent as described in the NRC (2001). Calculations from the BCS module were transferred to the average cow simulation and revenues and expenses modules.

\section{Reproduction module}

In this module, changes in costs associated with varying levels of reproductive performance were appraised. The effects of expected changes in reproductive performance associated with PDF technology adoption were calculated based upon the work of French and Nebel (2003a, b). This methodology was chosen because it considers the effect of multiple variables on the cost of a day open (DO) and reflects that the cost of a DO varies considerably depending on stage of lactation. The regression equation they developed, using differences in revenue for simulated farms of varying DO, was used to calculate the cost of DO, at a herd level, in this module. Inputs into this equation include stochastic milk, feed, replacement heifer, and cull cow prices, milk yield, break-even cull milk yield, DO, and DIM when cows were designated not to breed. Because the equation required feed cost per hundredweight of milk produced, the stochastic feed price was converted by assuming a ration of 60 percent dry matter with the average milk production and DMI from the herd demographics module. Days open were calculated using the equation described by Pecsok et al. (1994).

The cost per DO was calculated for each DO beyond 100 days and multiplied by the difference between predicted DO and 100 to produce a total of losses per cow from DO. This value was then multiplied by the number of cows in the herd, with an adjustment for a percentage of cows that were never considered for service, to provide total herd losses from DO. These calculations were conducted for two different scenarios:

(1) without the PDF technology; or

(2) with the PDF technology considering its impact on heat detection rate or conception rate.

The difference between the total costs of DO for the two scenarios was used to assess the increase in revenues from adoption of the PDF technology. The predicted DO was utilized in the herd demographics module to account for the impact of reproduction on herd dynamics.

The change in total DO resulting from reduced disease incidence was also calculated in this module. The changes in DO from diseases were modeled stochastically using a program evaluation and review technique (PERT) distribution using the published 95 percent confidence intervals and means from a meta-analysis examining the effect of disease on reproduction (Fourichon et al., 2000). The PERT distribution is a special case of a scaled beta distribution allowing for skewness using the minimum, mean, and maximum as inputs. For each disease, the stochastic DO value was multiplied by the number of cases eliminated with the PDF technology. This change in DO was added to the total herd DO without the technology and divided by the number of cows in the herd to provide a new average DO for the herd. Finally, the

Dairy business investment decisions 
AFR

70,1

106

total economic losses from DO were adjusted to reflect the improvement in reproductive performance associated with reduced disease incidence. However, because doing so would create a circular reference within the model (calving intervals impact culling which influence disease incidence), the adjusted DO did not feed back into the herd demographic module. In most cases, this value was small (e.g. $<1$ day), so it does not likely have a major impact on results through the herd demographics module. Results from this module fed into the average cow simulation, culling, and revenues and expenses modules.

\section{Disease cost modules}

The primary objective of the disease cost modules (retention pay-off (RPO), disease incidence, culling, disease milk loss, and other disease costs) was to estimate the costs of diseases. A PDF technology may reduce disease prevalence by providing useful information for preventative health practices. Alternatively, a PDF technology may reduce the impact of disease through earlier identification, which, in turn, may improve treatment effectiveness. The final output from these modules was quantification of the difference in losses from diseases with or without the PDF technology being evaluated.

\section{Disease incidence module}

Difficulties arise in analyzing disease data because clinical disease rates underestimate disease prevalence, with most disease manifesting itself in a subclinical form (Dohoo, 1993). There is tremendous variation in disease incidence because of differences in herd size, production, geography, and management. For many diseases, what actually constitutes a "case" of each disease in question is even debatable. Further, consistency in recording disease incidence was extremely variable, both within and among herds (Dohoo, 1993). Default disease incidence rates were chosen using recently published values for annual incidence rates from US herds (Table III). Individual users may change these rates to reflect herd-specific prevalence. For many diseases, incidence rates depend largely on parity. For example, the risk of a first lactation animal having milk fever is considerably lower than that of a fifth lactation animal. With this in mind, disease incidence rates can be entered at three different parity levels (1, 2, and $\geq 3)$. An assumption was made that the disease incidence rates remain constant throughout the ten-year analysis period. With the average cow model, the risk of disease was assumed

\begin{tabular}{lcc}
\hline Disease & Parity $1(\%)$ & Parity $\geq 2(\%)$ \\
\hline Displaced abomasum $^{\mathrm{d}}$ & 3.00 & 4.00 \\
Dystocia $^{\mathrm{e}}$ & 19.08 & $7.07 / 6.54^{\mathrm{a}}$ \\
Ketosis $^{\mathrm{d}}$ & 5.00 & 7.00 \\
Lameness $^{\mathrm{b}}$ & 13.50 & 13.50 \\
Mastitis $^{\mathrm{c} d}$ & 12.00 & 24.00 \\
Metritis $^{\mathrm{d}}$ & 8.00 & 4.00 \\
Milk fever $^{\mathrm{d}}$ & - & 2.00 \\
Pneumonia $^{\mathrm{d}}$ & 3.00 & 2.00 \\
RP $^{\mathrm{d}}$ & 6.00 & 11.00
\end{tabular}

Table III.

Default disease incidence rates

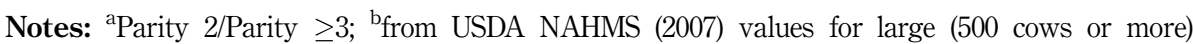
herds; ${ }^{c}$ value for first clinical mastitis case

Sources: ${ }^{\mathrm{d}}$ From Bar et al. (2007); ' from Dematawena and Berger (1997) 
constant across animals. In reality, the risk for many diseases is increased for higher producing animals than lower producing animals. Thus, the assumption made here was that, on average, the increased risk of disease for higher producing animals was balanced with a decreased risk of disease for lower producing animals.

A separate set of disease incidence rates may be used to represent the disease situation with the PDF technology. This may be accomplished either by changing the disease incidence rates for specific diseases directly or by altering the after adoption disease incidence rates using published risk ratios for a specific set of criteria. For example, the risk ratios for risk of ketosis for different BCS levels may be used in conjunction with the initial incidence rates to calculate a new ketosis rate reflective of conditions after adoption of a technology aimed at prevention of ketosis. The two sets of incidence rates were then used in the culling module for calculation of the number of disease cases.

\section{RPO module}

Methodology. Cost of culling is one of the most complex costs to account for in a dairy simulation model. In this module, the costs of culling, essential for calculating disease costs, were considered using the concept of a RPO. The results of this module were utilized in the culling module. The RPO calculations in this module closely followed the methodology described by Groenendaal et al. (2004) with some simplification to account for the herd-based nature of this model. Because the intent of this model was to examine decisions at a herd level, an RPO calculation was included to account for the average cost of culling for animals of varying ages rather than making individual cow culling decisions. Thus, in this module, marginal net revenues (MNR) were calculated on a monthly basis for the average cow in the herd during each year of the simulation using the deterministic price for the given year within calculations. A key assumption in the RPO calculation here was that the current average cow was replaced with an identical, albeit younger, average replacement. As with the Groenendaal model, this model assumed that the replacement heifer had an average calving interval and was kept until her maximal annuity was reached. A current animal within a herd provides a good estimate for expected replacement heifer net revenue (Groenendaal et al., 2004).

Marginal net revenues. Total revenues per month were calculated based on the total milk and calf revenues for 30-day periods beginning at the onset of the first lactation. Annual veterinary costs for a first lactation cow were set at $\$ 70$ (adjusted for inflation from (Groenendaal et al., 2004)) and assumed to increase by $\$ 5$ for each parity. Within lactation, 33 percent of veterinary costs were attributed to the first month of lactation, 11 percent to the second and third months, and 5 percent to later months (van Arendonk, 1985). Mortality costs were calculated by multiplying the cumulative mortality in a given month by the MNR for that month. Mortality risks based on work by Hadley (2003).

MNR for each month in the productive life of the animal were calculated as the sum of revenues (milk and calf) minus the sum of costs (feed, breeding, veterinary, and mortality) for each respective month. Although other revenues and costs could be considered, past work has indicated that these inputs have the largest impact on replacement decisions (Groenendaal et al., 2004). These MNR were then adjusted for the change in slaughter value from the previous month and the financial costs associated with idle production. The initial "slaughter" value at time 0 was established as the purchase price of a replacement heifer, under the assumption that even if heifers were raised on-farm the economic value of a replacement heifer was her market value.

\section{Dairy business investment decisions}


AFR 70,1
Slaughter prices $(\$ / \mathrm{kg})$ for each month were calculated by adjusting the deterministic cull cow price for thinness associated with cull dairy cows and by parity (100 percent for parities 1-3, 83 percent for parities 4-6, 74 percent for parities $\geq 7$ (Hadley, 2003) and multiplying this price by the average cow body weight for that month. The financial losses associated with not having an immediate replacement available were set at $\$ 50$ and multiplied by the marginal probability of disposal for each given month (Huirne et al., 1997b). The monthly MNR were then incorporated into the calculations for monthly annuity values and RPO. Revenues and costs were weighted with the probability of survival until the end of a given month and discounted using the overall model discount rate adjusted to a monthly rate reflecting a time preference of net revenue (Huirne et al., 1997b). The probabilities of survival within a given month of lactation were based on health culling rates calculated by Hadley (2003). The optimal replacement time was the first month where the annuity value of the cow dropped below the maximal annuity value of the replacement heifer (Groenendaal et al., 2004). The equations for calculating the annuity net revenue and retention-pay off were those described by Huirne et al. (1997b) and Groenendaal et al. (2004).

\section{Culling module}

Within this module, the impacts of selected diseases on culling and death were considered. The effects of mastitis, lameness, retained placenta, metritis, ketosis, milk fever, dystocia, and displaced abomasum on culling were modeled using risk ratios from Rajala-Schultz and Gröhn (1999). The basic premise of this module was that all animals have some base risk of being culled at any point in time and this risk increases by parity and with disease. The risks of culling for animals within the herd were compared to the base risk of culling for first lactation, non-diseased animals. The base culling rate included cows culled for reproductive failures, inferior production, conformation, and diseases other than those listed above. Because most of these culls would be based on producer decisions (voluntary rather than involuntary), the base culling rate was distributed equally throughout the lactation. The risk ratios for culling were 1.0, 1.4, 2.0, 2.6, 3.1, and 4.0 for parities $1,2,3,4,5$, and $\geq 6$, respectively (RajalaSchultz and Gröhn, 1999). All computations within this module were conducted separately for parities $1-5$ and $\geq 6$.

The risk ratios published by Rajala-Schultz and Gröhn (1999) accounted for both the timing of disease and the timing of culling within the following lactation intervals: 0-30 DIM, 31-60 DIM, 61-150 DIM, 151-240 DIM, and greater than 240 DIM. Both the timing of disease (DISTIME) and the timing of culling (CULLTIME) were considered separately in each of these lactation intervals. The advantage of using these ratios was that they not only account for the timing of disease among these intervals within a lactation but also how disease timing affects subsequent culling risks among these same intervals. When a disease occurs at one stage of lactation, the risks of culling changed, not only for that period, but also for the remainder of lactation. For each disease and parity combination, the risk of culling was adjusted for each lactation DISTIME and CULLTIME combination using a modified version of an equation developed by Grohn et al. (2003) (Rajala-Schultz, personal communication):

$$
\mathrm{RC}_{i j}=\left(\left(\mathrm{BC}_{j} /\left(1-\mathrm{BC}_{j}\right)\right) \times \mathrm{OR}_{i j}\right) /\left(1+\left(\mathrm{BC}_{j} /\left(1-\mathrm{BC}_{j}\right)\right) \times \mathrm{OR}_{i j}\right),
$$

where $\mathrm{RC}_{i j}$ is the risk of culling for disease $i$ at (DISTIME $\times$ CULLTIME) $j, \mathrm{BC}$ is the base culling rate for (DISTIME $\times$ CULLTIME) $j$, and $\mathrm{OR}_{i j}$ is the risk ratio for 
disease $i$ during (DISTIME $\times$ CULLTIME) $j$. Accounting for disease in this manner ignored repeated cases of a disease and interactions between diseases. Though both situations most certainly exist on every dairy farm, values from the literature to describe these relationships were varied and these calculations were beyond the scope of this model.

The total number of cases for each disease within parity was calculated by multiplying the incidence rate from the disease incidence module by the number of cows in the herd within each respective parity at the beginning of each year. Next, this value was used to calculate the number of cases of each disease occurring during each DISTIME. The distributions for timing of diseases defined by Kinsel (1998) were utilized to distribute the occurrence of disease cases among DISTIME. Accounting for the timing of diseases in this manner provides a means of assessing the different effects a disease may have depending on the stage of lactation in which it occurs. Within each DISTIME, the risk of culling changes for subsequent CULLTIME. The percentage of the entire herd culled for each DISTIME by CULLTIME interaction was then calculated using these disease-adjusted culling risks and number of disease cases. These percentages were summed across all diseases and with non-diseased cows to result in an overall culling rate. Similarly, the number of cows culled per DISTIME by CULLTIME interaction within each disease and parity were summarized. After the number of culls for each parity within each year was calculated, these numbers were transferred to the herd demographics module where they altered herd dynamics for the subsequent years.

The RPO values from the retention pay-off module for each CULLTIME were used to calculate the total costs of premature culling for the cows removed from the herd in each category. However, to account for the disease-attributable costs of culling, an adjustment should be made. Even without disease, there is a base risk that the cow would be removed from the herd prematurely for other reasons. Thus, the value of interest for calculation of disease costs is the incremental costs of culling associated with disease occurrence. To calculate this value, the number of culls resulting from the increased risk of disease was multiplied by the RPO per cow. As an example, assume that the base risk of culling for a particular disease that occurs in the first 30 days of lactation during the same interval was 1 percent, the RPO was $\$ 1,000$, and the number of cases was 100. A case of mastitis increased the risk of culling during this lactation interval to 2 percent. Two cows would be culled during this period leading to a total cost of premature culling of $\$ 2,000$. One of these cows would have been culled regardless of disease occurrence; therefore, the disease-associated costs of culling were $\$ 1,000$ rather than $\$ 2,000$.

An additional cost was incurred if the affected cow died on farm rather than being sold for slaughter. This lost income was also accounted for in this module. The percentages of cases of disease resulting in death are as reported by Guard (1998). These percentages were multiplied by the number of cases of disease to calculate the number of deaths resulting from disease occurrence. The average by-parity slaughter values from the RPO module were then used to estimate the additional costs from culling due to death beyond RPO because of the lost potential income. The total costs from premature culling, total disease-attributable costs from premature culling, and total death costs were summarized by disease within DISTIME. The final outputs from this module were average culling and death costs per case for each disease.

In comparisons of scenarios with and without a PDF technology, the differences in disease incidence were tabulated in this module. The RiskData function of @ Risk was

\section{Dairy business investment decisions}


AFR 70,1 utilized to count the differences in the number of disease cases between the two scenarios. For six parity categories (1-5 and $\geq 6$ ), this difference was calculated for each disease each year. The risk ratios for culling risk associated with disease may be adjusted in this module for technologies with potential to reduce this risk. The RiskSimTable function of @ Risk was used for simulation of scenarios with the technology, reflecting reduced risk ratios, and without the technology, reflecting default risk ratios. Additionally, for PDF technologies that could reduce the impact of a disease through earlier detection, for example, the percentage of cases of disease resulting in death may be adjusted in this module.

\section{Disease milk loss module}

In this module, the differences in losses from unrealized milk production between scenarios with and without PDF technologies were examined. Losses in milk production were considered separately for first parity and second or greater parity animals as reported in recent work from New York (Bar et al., 2007). The mean and 95 percent confidence interval for weekly losses reported were modeled stochastically as the minimum, mean, and maximum losses in milk production within a PERT distribution. Although those authors reported gains in milk production associated with some diseases as the time from disease occurrence increased, these gains were not modeled in our work. When a minimum, mean, or maximum was listed as positive, it was set to zero in this module. The assumption made was that these gains were the result of higher-producing cows being more susceptible to disease rather than the disease inducing an increase in milk production. These cows had greater genetic potential, which was eventually realized again after the animal recovered from the disease.

The potential gains in milk production from reducing the prevalence or impact of each disease were calculated weekly. The change in number of disease cases from the culling module was distributed among weeks using the aforementioned disease timing distributions (Kinsel, 1998). Clearly, given the modest prevalence of some diseases this resulted in fractions of cases rather than whole cases. Then, the weekly number of reduced disease cases was multiplied by the potential gains in milk production for a case occurring during that week resulting in a total gain in milk production from reduced disease incidence or impact. This process was repeated for each week in the lactation. In this manner, elimination of a case of disease in later lactation would have less of an impact than elimination of a disease in early lactation. The total gain in milk production from influence on each disease was totaled and averaged. If the proposed PDF technology reduced the impact of a disease, this reduction was accounted for here. Next, the value of this increased milk production was accounted for using the stochastic milk price for a given year. However, because this milk was actually never produced, it was important to subtract the cost of reduced DMI. To accomplish this, the average ratio of DMI to milk production was multiplied by the stochastic feed price for the year. Ultimately, the final output from this module was a net gain in revenue, transferred to the revenues and expenses module, from increased milk production associated with technology adoption accounting for reduced DMI.

\section{Other disease costs module}

Estimates for veterinary and drug costs, labor, and milk discarded associated with disease have not been studied extensively. Certainly, one of the reasons for a lack of estimates for these parameters is within farm variation. In this module, the estimates 
for these parameters provided by Guard (1998) were adjusted to 2,006 dollars to reflect cost increases over time. In recognition of there being some variation associated with these costs, each was modeled stochastically with a normal distribution using a standard deviation (SD) calculated at a 10 percent coefficient of variation from the base value. Stochastic labor and milk prices from the stochastic variables module were used within calculations for the labor costs and milk discarded. Unlike with unrealized milk production, the feed costs were not subtracted from milk discarded because these feed costs were still incurred. For a PDF technology with potential to reduce disease incidence, the reduced number of cases of disease were multiplied by per case veterinary and drug, labor, and milk discarded costs, respectively, to estimate revenues from technology adoption. For a technology with potential to reduce the impact of a disease, the estimated impact reduction was multiplied by each of these costs and then by the total number of cases to estimate revenues. These revenues were then transferred to the revenues and expenses module.

\section{Revenues and expenses module}

In this module, all revenues and expenses resulting from investing in a PDF technology over the ten-year investment period were collected. Using a partial budget approach, only revenues and expenses that were affected by the technology in question were considered. Considering other factors would create unnecessary complication of the model (Hyde and Engel, 2002). Reductions in losses, resulting from investing in a PDF technology, from the following categories were considered as revenues: culling, death, veterinary and drug, labor, discarded milk, unrealized milk gain, reproduction, energy efficiency, and technology specific savings. Inflation was built into the revenues through the stochastic simulation of milk, replacement, slaughter, and feed prices. Expenses were generally technology specific but included items such as annual maintenance fees, replacement parts, labor costs, or utility costs.

The RiskData function of @ Risk was used to calculate the differences in all diseaseassociated culling and death costs between the two scenarios from the culling module. Any reduction in losses was considered as revenue whereas any increase in losses was an expense. Veterinary and drug, labor, and milk discarded savings were derived directly from the other disease costs module. Savings from reductions in diseaseassociated milk loss, gains in reproductive efficiency, and improvements in energy efficiency originated in the disease milk loss, reproduction, and energy efficiency modules, respectively.

In animal health economics, the large gap between what is planned and what is implemented with a particular control strategy is often ignored (Perry and Randolph, 1999). Although there is probably no direct way to account for the multitude of decisions that ultimately impact the actual profitability of an investment in a PDF technology, this model included a best management practice adherence factor (BMPAF) to proxy the potential for observing the maximum benefits from adopting a technology. The BMPAF was a crude scale from 1 to 100 percent designed to represent the level of the farm management. At a value of 100 percent, the assumption was that the farm management was capable and likely to utilize the technology to its full potential. Consequently, they would observe the maximum benefit from the technology. On the other end of the spectrum, a value of 0 percent represented a scenario where farm management installed a technology without changing management to integrate the newly available data in efforts to improve herd performance. In this case, the farm would not recognize any of the benefits of the technology. As a proxy for management

\section{Dairy business investment decisions}


AFR 70,1

level, the mean RHA milk production was divided by the mean plus two SD for Holstein herds with at least 500 cows from a DairyMetrics (DRMS, Raleigh, North Carolina) report calculated on January 27, 2008. This resulted in a 77 percent default BMPAF. The basic reasoning for this calculation was that higher milk production is generally associated with improved management capacity; consequently, the ratio of average milk production compared with maximum potential milk production should be proportional to differences in management capacity. Perhaps most importantly, sensitivity analyses allow the end user to evaluate the decision with knowledge of the role they play in its success. Practically, the BMPAF was modeled by simply multiplying the revenues modeled to this point by the BMPAF, reducing the potential revenues from the technology accordingly.

\section{Project analysis module}

In this module, the profitability and financial feasibility of investing in the PDF technology were examined. The NPV was the metric used to assess the profitability of the investment. The time value of money, reflecting that a dollar today is worth more than a dollar tomorrow, was accounted for in this analysis using an arbitrary default discount rate of 8 percent. The discount rate represents the returns from alternative uses of capital. With this discount rate, the requirement was set that returns to the investment must be at least 8 percent for this to be an acceptable investment. Any investment must provide sufficient returns to compete with alternative uses of capital (Galligan, 1999). The general rule of thumb is a decision with a NPV greater than zero is a "go" decision and a worthwhile investment for the business. When the costs of collecting and processing data obtained from a PDF technology exceed the benefits, the system should not be purchased (Huirne, 1990).

An option to increase the discount rate, reflecting increased risks, for proposed or new technologies was also included with default increases of 2 percent for proposed technologies and 1 percent for new technologies. If the objective of a research project is to conduct an investment analysis for a new technology that has not been commercially adopted, some assumptions may be demonstrated as inaccurate as more is learned about a particular technology (Hyde and Engel, 2002). Revenue and expense flows were obtained directly from the revenues and expenses module. The default depreciation was straight-line depreciation over a five-year period. Larger depreciation allowances such as those allowed by accelerated depreciation rules would result in higher NPVs because of the larger tax shield in early years. The investment at the beginning of the project included the purchase costs of the equipment needed to run the system in addition to purchasing any other setup costs or purchases required to start the system. Taxes were calculated using the 35 percent tax rate. Net cash flows were collected and adjusted by their respective discount rates. Finally, the NPV was calculated by collecting the discounted cash flows.

To this point, the results discussed only provided a point estimate of the NPV of investing in a PDF technology. Recognizing that a deterministic model ignores the uncertainty inherent in a dairy system, the real value of this model is through Monte Carlo simulation using the @Risk add-in. Through multiple iterations through the basic model, a series of trials, in the form of model iterations, can be run to determine the probability of success for the project. For example, it is possible to determine the percentage chance that a positive NPV will be obtained. Further, sensitivity analyses, designed to evaluate the range of potential responses, provides further insight into an investment analysis (van Asseldonk et al., 1999). 
In addition to the profitability of the investment, the decision maker should also be concerned about the financial feasibility of the project. This module determined if the project will cash flow. The amount of the loan (equal payments) was calculated with a 0 percent down payment over the ten-year period of the project using the interest rate input by the user. Annual cash flows were carried over from the investment analysis. The payment schedule was adjusted to an after-tax basis. Annual net cash flows were compared to after-tax annual principal and interest payments to determine if a cash surplus or deficit will occur.

\section{Simulation examples}

The main objective of this publication was to describe the basic structure and methodology of a model describing a dairy system over ten years. Subsequent publications will examine the application of this model toward profitability analysis of specific PDF technology examples. For this publication, a series of simulations were run for subsets of the full model to examine results for stochastic prices, disease costs, DO costs, and RPOs. In each simulation, Latin Hypercube sampling was used with a fixed seed of 31,517 to ensure all simulations provided repeatable results. For stochastic prices, 1,000 iterations of a simulation were run for milk, replacement heifer, cull cow, corn, soybeans, and alfalfa prices for the ten-year period. Simulations focused on stochastic variables for disease costs, DO, and RPOs involved 5,000 iterations for the year 2007 only. Sensitivity analyses for deterministic model inputs were conducted using the advanced sensitivity analysis function of @ Risk. For each influential deterministic input, 250 iterations were run at extreme minimum and maximum values.

\section{Results and discussion}

Adoption of sophisticated on-farm decision-making tools has been scant in the dairy industry to this point. Yet, the dairy industry remains a perfect application of decision science because:

- it is characterized by considerable price, weather, and biological variation and uncertainty;

- technologies, such as those characteristic of PDF, designed to collect data for decision making abound; and

- the primary output, fluid milk, is difficult to differentiate, increasing the need for alternative means of business differentiation.

In deterministic, single-output models, results are presented without consideration of price and production risk. In reality, every dairy producer recognizes that the profitability of any investment or decision will vary considerably depending on what combination of prices eventually occur. Although prices can never be predicted perfectly, through multiple iterations of simulation models, the variation in prices can be accounted for to provide an indication of how combinations of events will affect the probability of obtaining a desirable financial result. Under the model assumptions, using FAPRI projections as deterministic prices and historical trends to estimate variation and correlations between prices, it was clear that there was considerable variation in each of these six prices. For example, milk prices varied from $\$ 0.25 / \mathrm{kg}$ to almost $\$ 0.40 / \mathrm{kg}$ each year and corn prices vary from $\$ 0.11 / \mathrm{kg}$ to $\$ 0.13 / \mathrm{kg}$. Interestingly, for milk price and cull cow price, key determinants of farm revenues, there appeared to be slightly more upside risk, comparing the width of the band
Dairy business investment decisions 
AFR 70,1

between the $+1 \mathrm{SD}$ and maximum to the width of the band between the $-1 \mathrm{SD}$ and minimum. Conversely, for costs, because higher values are less desirable, there appeared to be more downside risk for replacement heifers, corn, and soybeans. The next step was to investigate how these stochastic prices ultimately affected some of the critical calculated costs important to decision making, culling, DO, and disease.

In sensitivity analyses, the tornado diagram visually portrays the effect of either deterministic or stochastic variables on an output of interest. The results of any simulation model are highly dependent on the assumptions within the model. A oneway sensitivity analysis tornado diagram compares multiple variables on the same graph. Essentially, each input is varied (one at a time) between feasible high and low values and the model is evaluated for the output at those levels holding all other inputs at their default levels. On the tornado diagram, for each input, the lower value is plotted at the left end of the bar and the higher value at the right end of the bar. The lengths of the bars are representative of the sensitivity of the output to each input. The tornado diagram is arranged with the most sensitive input at the top progressing toward the least sensitive input at the bottom. In this manner, it is easy to visualize and compare the relative importance of inputs to the results of the model.

\section{$R P O$}

Assessing the cost of culling on dairy farms is a complex and controversial issue. In some spreadsheet models, the cost of culling is calculated simply as the difference between the price received from marketing the cull cow for slaughter and the price paid for her replacement. Although this calculation accurately reflects the financial costs of culling, it does not reflect the economic costs of culling. Using a MNR technique, previous researchers (Huirne et al., 1997b; Groenendaal et al., 2004) have calculated the cost of culling, and discussed extensively the economic theory and associated assumptions, using the concept of a RPO. This concept compares the expected MNR from a cow with the economic opportunity of her replacement. Groenendaal et al. (2004) defined the RPO as the "total additional profits that a producer can expect from trying to keep the cow until her optimal age, taking into account the changes of involuntary removal compared with her immediate replacement." The RPO is also the maximum money that a producer should spend to try to keep the cow in the herd. When the RPO is positive, the value indicates the amount of money the producer should be willing to spend to keep the animal in the herd. When the RPO is 0 or negative, this indicates that the optimal decision is to replace the cow at that time.

In Figure 1, the trends for RPO throughout the productive life of a dairy cow are depicted. As reported by Groenendaal et al. (2004), the RPO followed a distinct withinlactation pattern with RPO being highest just before each calving and lowest between seven and nine months after calving. The RPO were much more sensitive to stochastic prices within the model earlier in the animal's life than later as indicated by the higher SD and wider confidence interval. This phenomenon was partially explained by the increased scale of early life RPO. Further, the effects of changes in price were multiplied when future revenues were accrued over a longer time horizon for younger animals compared with a shorter time horizon for older animals. During the first lactation, the cost of culling varied by as much as $\$ 400$ depending on the current and future prices simulated. As the animal aged, this impact was diminished considerably. As the animal aged, the RPO decreased considerably reflecting that eventually, from an economic perspective, the optimal decision was to replace the cow with a more valuable younger animal. 


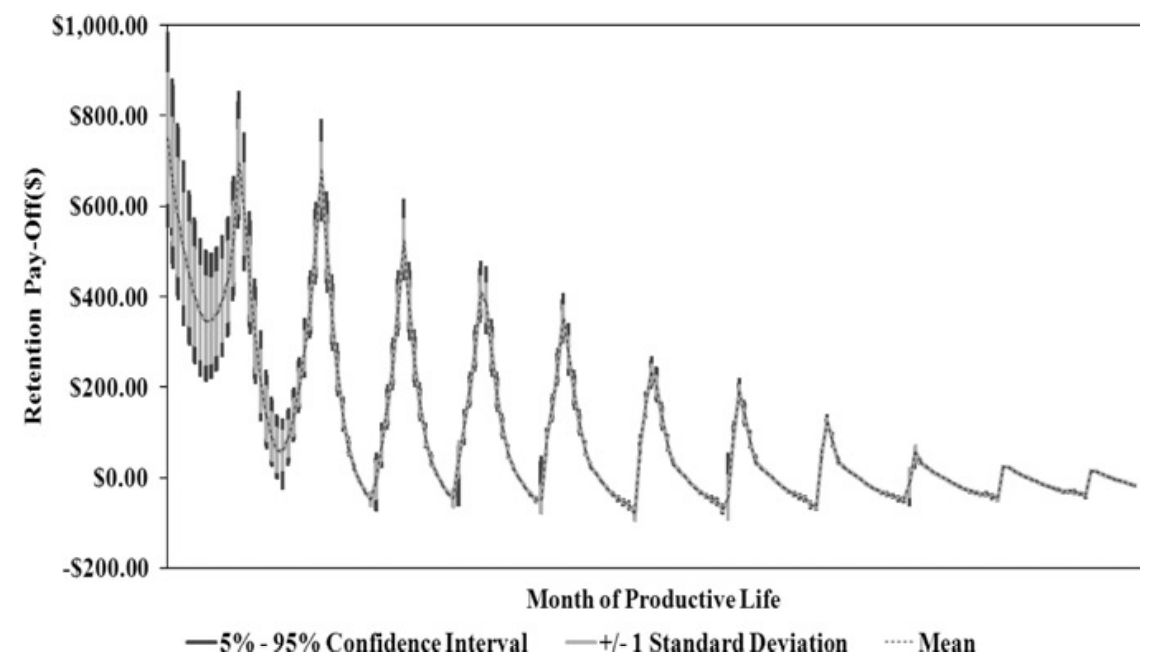

\section{Dairy business investment decisions}

In Figure 2, a one-way sensitivity analysis tornado diagram is presented for the RPO during the first month of productive life for an average cow in 2007 using the model assumptions. From this graph, we can discern that the most critical inputs affecting this particular RPO were the values assigned to heifer calf value, mature body weight, bull calf value, rolling herd milk production, and age at first calving. The other inputs in the model had minimal impact. The values assigned for the heifer and bull calves were influential because of the way that they affected revenues early in the animal's life. When a high value was assigned to either, the animal recognized more revenues earlier in life. As a result, the maximum annuity net revenue occurred earlier in life, which, in turn, reduced the first optimal moment for replacement and the value of keeping the cow in the herd for a longer period. Mature body weight influences the RPO in two ways. First, the larger cow consumed more DMI, which increased feed costs and reduced MNR. On the other hand, the larger cow had more potential income when slaughtered. This factor turned out to have more influence on the RPO. The value of keeping the larger cow in the herd longer was lower because of increased revenues at slaughter. The average production level influenced RPO. When production was higher, the RPO was lower reflecting that revenues early in life were higher reducing the time to optimal age of replacement. Lastly, calving cows for the first time at a young age reduced DMI earlier in life resulting in a slight increase in early life MNR. In turn, this reduced the value of keeping the animal in the herd longer, holding all other variables constant. This result may not be entirely reflective of reality because it assumed the same production level for first lactation animal's regardless of age at first calving.

Sensitivity analyses were performed for the factors affecting RPO during the first month of the first lactation. For parity one, increasing replacement price by one SD increased the RPO by $\$ 196.39$. This result demonstrated that if the cost of a replacement heifer was elevated, there was more value in keeping other animals in the herd longer. Conversely, increasing slaughter price, milk price, or feed cost by one SD decreased the cost of replacement by $\$ 80.08, \$ 9.02$, and $\$ 2.16$, respectively. When the slaughter price was higher, more revenue was recognized from culling the cow; thus, there was less value in keeping the cow in the herd longer. When milk price was higher, more revenues were recognized earlier in the cow's life reducing the value of longevity. 


\begin{tabular}{l} 
AFR \\
70,1 \\
$\mathbf{1 1 6}$ \\
\hline
\end{tabular}

Figure 2.

Tornado diagram for deterministic factors affecting RPO during the first month of productive life

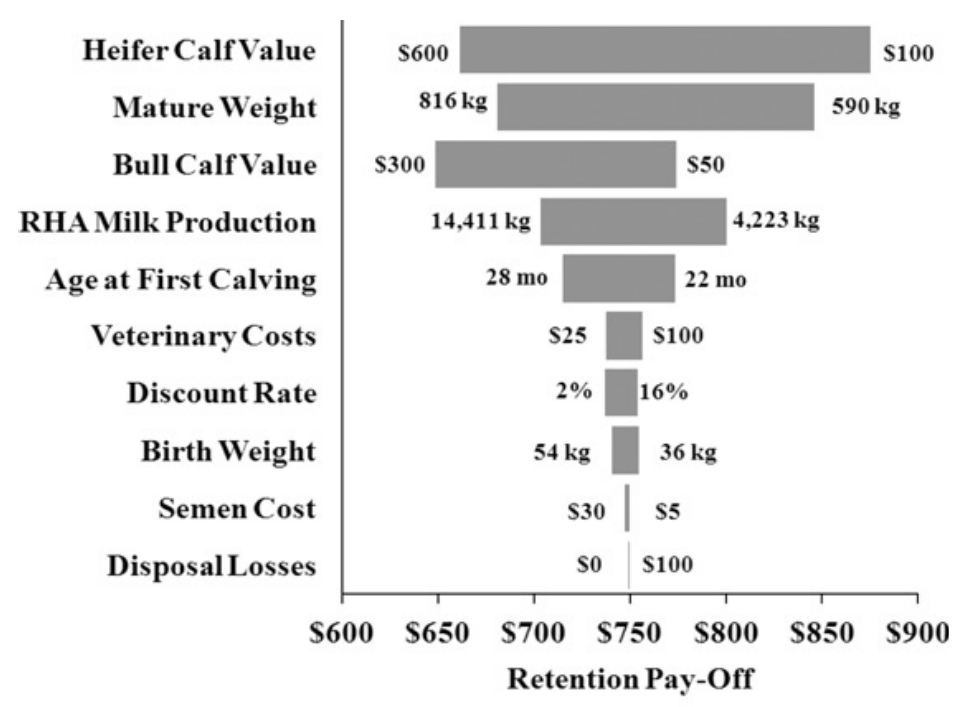

Notes: RPO for the first month of productive life for an average cow in 2007 under model assumptions; values on either side of the bar represent the lowest or highest value simulated for each input

Lastly, when feed costs were higher, fewer revenues were recognized early in life, reducing the time of the maximum annuity of net revenue. This increased the optimal age of replacement resulting in a higher RPO. Interestingly, the relative effects of these four prices changed as the animal aged. The replacement price had progressively less impact on the RPO whereas the other prices, milk price in particular, had a much greater influence on the RPO. The replacement price had less influence because the primary financial impact of the replacement price was recognized in the first productive life month where the market value of the cow was reduced from the value of a replacement heifer to the slaughter value of a first parity cow in the first month of lactation. As milk price increased, there was more value in keeping the animal in the herd longer at higher production levels because of increased revenues.

In a regression tornado diagram, @ Risk runs a multiple regression analysis for each iteration with the output of interest as the dependent variable and the simulated values of each stochastic variable as independent variables. The resulting graphs depict beta coefficients, which demonstrate the amount of change in the dependent variable when the independent variable increases by one $\mathrm{SD}$ with all other variables held constant (Winston, 2001). In Figure 3, a regression tornado diagram is depicted that quantifies the impact of these four prices on the first optimal moment for replacement age. This was an important number to consider because it demonstrated the minimum length of time that a cow should remain in the herd. When the cow survived to a subsequent lactation, the optimal time of replacement increased. The optimal moment for replacement increased by 6.88 months when the replacement price increased by one SD. In other words, when replacement heifer prices were higher, there was more value in keeping the cow in the herd for a longer period. When milk price and slaughter price increased by one SD, the optimal times for replacement decreased by 3.90 and 3.68 months, respectively. Higher milk prices and slaughter prices reduced the 


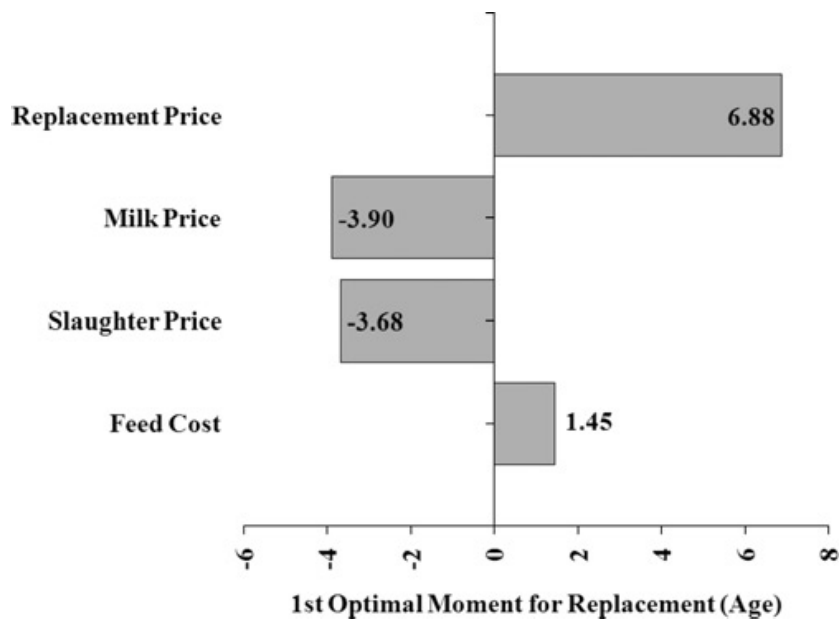

\section{Dairy business investment decisions}

Figure 3.

Tornado diagram for stochastic factors affecting first optimal age of replacement

optimal herd life. Increasing feed costs by one SD increased the optimal time for replacement by 1.45 months.

For these example simulations, within an iteration, a single stochastic milk price is used for all RPO calculations, which will predict consistently high or low milk prices in some iterations. For technology investment examples, the deterministic milk price for a given year is used in a similar manner. Changing milk prices to reflect the dynamic nature of milk price within the RPO module would be overly complex and computationally near impossible to calculate given the dynamic nature of these equations and assumptions necessary for calculation with this methodology. In reality, within an individual animal's life, the price of milk varies and that dynamic was not captured here. Nevertheless, these graphs demonstrated the impact of prices on the cost of culling.

\section{Cost of days open}

Reproductive efficiency is a primary determinant of productivity and profitability on dairy operations. Calving interval, DO, days to first service, estrus detection rate, and conception rate are all utilized to describe reproductive efficiency in the dairy herd (Skidmore, 1990). Optimal calving intervals have been estimated to be between 310 and 400 days, largely dependent upon the assumptions and criteria used in evaluations (Huirne et al., 2003).

The impact of reproductive losses also varied with changes in stochastic prices. In Figure 4, a regression tornado diagram for the impact of slaughter, feed, replacement, and milk prices on cost per DO is presented. As feed costs and slaughter prices increased by one SD, the cost of a DO decreased by $\$ 0.24$ and $\$ 0.23$, respectively. Conversely, when replacement prices and milk price increased by one SD, the costs per DO increased by $\$ 0.20$. Higher slaughter cow prices lessened the impact of culling cows early whereas higher feed costs reduced the margin from the increased milk production. When replacement prices were higher, more damage was caused by premature culling whereas higher milk prices increased the benefits of higher milk production associated with shorter calving intervals.

From Figure 5, depicting a one-way sensitivity tornado diagram of model inputs, it is apparent that the cost of a DO was highly dependent on these inputs. Not 
AFR

70,1

118 surprisingly, the cost of a DO increased considerably with decreasing conception rate or heat detection rate. The costs of a DO were lower when the voluntary waiting period was shorter and when milk production was lower. This demonstrated the importance of beginning to breed cows as soon as possible after calving. Although it may seem counterintuitive, higher milk production increased the costs of a DO because the impact of having cows spend more time in the later stages of lactation when production was lower was even greater. Obviously, this result was highly dependent on the shape of the individual cow's lactation curve. Lastly, the cost of a DO was higher if the producer designates the cow "do not breed" earlier in the lactation and if the break-even cow milk yield was lower.

\section{Cost of disease}

One of the purported benefits of PDF technologies is the prevention or amelioration of the impact of disease. Considering disease impact in an economic simulation is essential because of the dramatic effects disease can have on nutrition, reproduction, milk production, and involuntary culling through mortality and morbidity (Skidmore, 1990; Rushton et al., 1999). In addition to these major, commonly discussed effects of disease, "invisible losses" such as a reduced number of calves born, resulting from decreased fertility, impact the economic efficiency of an animal production system (Rushton et al., 1999). The primary challenge in accomplishing this goal is finding quality data to use as inputs in economic analysis (Marsh, 1999). Literature useful for assessing the costs of disease is often lacking, because it is not detailed enough, based on case studies, or fails to consider the time component of disease (Bennett, 2003). Additionally, the epidemiological studies needed to obtain accurate, robust values for model assumptions are expensive and time consuming. The dearth of information on this topic was surprising to the authors. Much of this research was less than desirable because it was performed in other countries, in different production systems, or many years ago.

The results of our work for the costs of disease, like all others, were highly dependent on the assumptions used in the model. These results were based on a simulation using 2007 prices with all inputs at default levels. Ideally, all of the

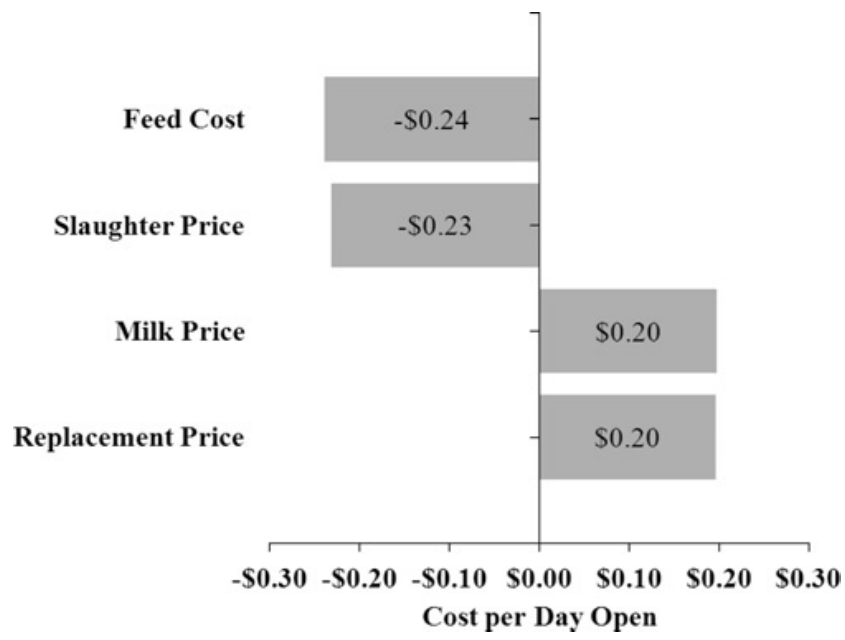

\section{Figure 4 .}

Tornado diagram for stochastic factors affecting cost per DO 


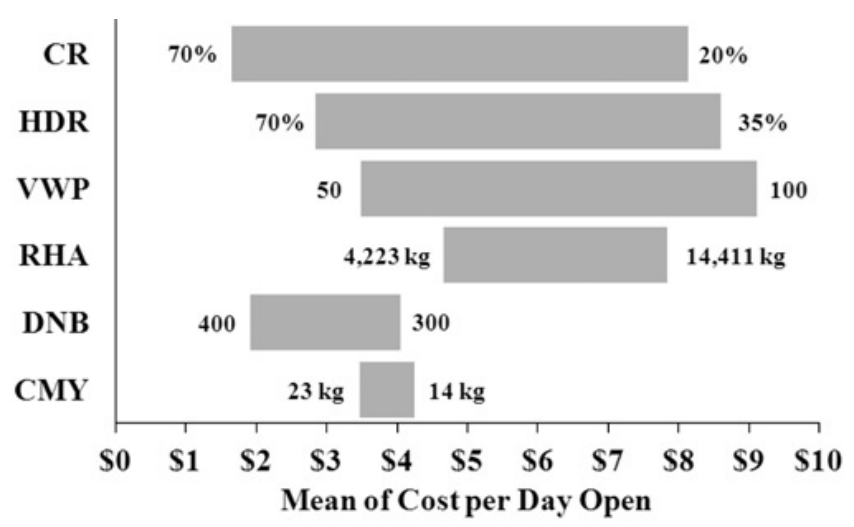

Notes: CR is conception rate; HDR is heat detection rate; VWP is voluntary waiting period; RHA is rolling herd average milk production in $\mathrm{kg}$; DNB is DIM designated do not breed; and CMY is daily milk yield designated to cull a cow; values on either side of the bar represent the lowest or highest value simulated for each input
Dairy business investment decisions

119

assumptions would come from the same database of information reflective of US conditions derived from multiple herds and many animals. However, this was not possible due to a lack of information. The simulated costs of displaced abomasum, dystocia, ketosis, mastitis, metritis, milk fever, and retained placenta for parity one and parity $\geq 2$ are presented in Table IV. The manner in which these costs were distributed between veterinary and drug costs, lost milk, labor, discarded milk, death, DO, and culling is presented in Figure 6 for parity one and $\geq 2$. For parity one, the mean cost of disease was highest for displaced abomasum followed by metritis, mastitis, retained placenta, dystocia, and ketosis. For parity two, the highest cost was also for displaced abomasum followed by metritis, retained placenta, mastitis, dystocia, milk fever, and ketosis. Generally, costs were higher for diseases in older animals, because of increased losses from unrealized milk production. From Table IV, it was also clear that the amount of variation in the costs of each disease was noteworthy. It is important to note that the costs were those directly attributable to a particular disease. Considering that, the occurrence of one disease may affect the occurrence of another, which is not accounted for in this model, could change the results some.

The cost of a displaced abomasum was most sensitive to the resulting change in DO, the replacement heifer price, and the veterinary and drug costs for parity one and to the resulting change in DO, milk price, and unrealized milk production for parity $\geq 2$. For dystocia, the most influential variables were replacement prices and veterinary and drug costs. The cost of a case of ketosis was influenced most by the resulting change in DO, replacement price, and veterinary and drug costs for parity one cows and to unrealized milk production, milk price, and increased DO for parity $\geq 2$. The cost of a case of mastitis was sensitive to milk price, replacement price, unrealized milk, and feed costs for parity one cows and milk price, unrealized milk, feed costs, and replacement costs for parity $\geq 2$. For metritis, the costs were most sensitive to milk price, replacement price, and slaughter price for parity one and to unrealized milk, milk price, and replacement price for parity $\geq 2$. Retained placenta costs were most sensitive to milk price, feed costs, and unrealized milk production for both parity groups. Finally, 
AFR

70,1

120

the costs of milk fever, only calculated for parity $\geq 2$ were most sensitive to the resulting change in DO, replacement price, and veterinary and drug costs.

Within published literature, disease costs tend to be published as deterministic estimates ignoring the impact of prices and inputs within calculations. These estimates demonstrate that the cost of disease varies considerably with varying disease impacts, veterinary and drug costs, and milk, feed, and replacement cow costs. In decision support systems, accounting for this variation improves the precision and acceptability of results. Optimal decisions, with regard to animal health, fluctuate with changing market and farm-specific conditions. Robust epidemiological studies, designed to estimate the impact of disease should be conducted to improve the accuracy of estimates for disease impact. Furthermore, disease costs estimates and recommendations should consider variation in milk, replacement, feed, and cull cow prices.

Most research on the economics of disease control on dairy farms has focused on estimating production losses or disease eradication programs, whereas relatively little emphasis has been placed on determining optimal levels of preventive action (McInerney, 1996). One of the primary criticisms of discussions of the impact of animal health interventions is that they tend to discuss interventions as if they will eliminate

\begin{tabular}{|c|c|c|c|c|}
\hline Disease & Minimum & Mean & Maximum & $\mathrm{SD}$ \\
\hline \multicolumn{5}{|l|}{ Parity 1} \\
\hline Displaced abomasums & $\$ 130.16$ & $\$ 266.20$ & $\$ 451.42$ & $\$ 43.26$ \\
\hline Dystocia & $\$ 116.20$ & $\$ 146.18$ & $\$ 186.90$ & $\$ 8.99$ \\
\hline Ketosis & $\$ 55.44$ & $\$ 78.35$ & $\$ 111.50$ & $\$ 7.61$ \\
\hline Mastitis & $\$ 133.65$ & $\$ 205.95$ & $\$ 315.86$ & $\$ 23.61$ \\
\hline Metritis & $\$ 168.96$ & $\$ 210.77$ & $\$ 270.39$ & $\$ 12.67$ \\
\hline Retained placenta & $\$ 125.74$ & $\$ 179.16$ & $\$ 271.25$ & $\$ 19.84$ \\
\hline \multicolumn{5}{|l|}{ Parity 2} \\
\hline Displaced abomasums & $\$ 215.34$ & $\$ 380.78$ & $\$ 603.00$ & $\$ 52.98$ \\
\hline Dystocia & $\$ 118.25$ & $\$ 144.24$ & $\$ 177.20$ & $\$ 8.03$ \\
\hline Ketosis & $\$ 69.11$ & $\$ 105.89$ & $\$ 167.11$ & $\$ 13.43$ \\
\hline Mastitis & $\$ 111.73$ & $\$ 163.28$ & $\$ 250.73$ & $\$ 18.16$ \\
\hline Metritis & $\$ 217.53$ & $\$ 295.32$ & $\$ 440.60$ & $\$ 34.24$ \\
\hline Milk fever & $\$ 71.75$ & $\$ 114.08$ & $\$ 171.89$ & $\$ 15.14$ \\
\hline Retained placenta & $\$ 126.83$ & $\$ 167.60$ & $\$ 236.94$ & $\$ 13.97$ \\
\hline
\end{tabular}

Table IV.

Simulated minimum, mean, and maximum total disease costs over 1,000 iterations
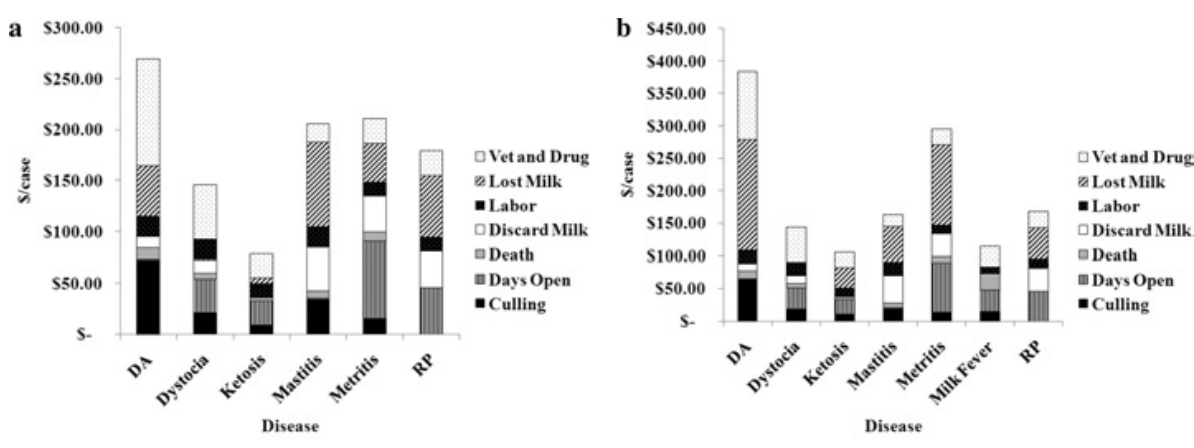

Notes: DA is displaced abomasum and RP is retained placenta

\section{Figure 6.}

Distribution of sources of (a) first parity and (b) second parity (and greater) disease costs by disease 
the deleterious effects of the diseases in question. For example, in marketing efforts for animal health technologies, disease costs may be multiplied by herd incidence rates to provide an estimate of potential technology benefits. However, this type of analysis assumes that the impact of disease is completely eliminated rather than reduced to some degree resulting in a gross overestimate. Such calculations provide inflated estimates of the value of interventions and reduce producer acceptance of economic decision-making tools. To address this concern, this model considers that only a fraction of the disease will be detected by the technology and that identifying the disease will only influence a portion of the losses typically associated with a disease. Perhaps, the most important adjustment was the consideration and focus on the reduction in losses from disease rather than the total cost of disease.

\section{Conclusions}

A stochastic simulation model designed to examine the benefits associated with investments in PDF technologies was developed and described in detail. Examples of the utility of examining the influence of stochastic input and output prices on the costs of culling, DO, and disease were examined. This model may be applied, in future research and commercial efforts, to explore investment decisions for specific technologies. Decision support tools, designed to investigate dairy herd decisions at a systems level, such as this one, may benefit the well-being of dairy producers once barriers to adoption are addressed.

\section{References}

Bailey, K. and Ishler, V. (2007), Dairy Risk-management Education: Tracking Milk Prices and Feed Costs, Pennsylvania State University, University Park, PA, p. 6.

Bar, D., Grohn, Y.T., Bennett, G., Gonzalez, R.N., Hertl, J.A., Schulte, H.F., Tauer, L.W., Welcome, F.L. and Schukken, Y.H. (2007), "Effect of repeated episodes of generic clinical mastitis on milk yield in dairy cows", Journal of Dairy Science, Vol. 90, pp. 4643-53.

Bennett, R. (2003), "The 'direct costs' of livestock disease: the development of a system of models for the analysis of 30 endemic diseases in Great Britain", Journal of Agricultural Economics, Vol. 54, pp. 55-71.

Bewley, J.M., Boyce, R.E., Roberts, D.J., Coffey, M.P. and Schutz, M.M. (2010), "Comparison of two methods of assessing dairy cow body condition score", Journal of Dairy Research, Vol. 77, pp. 95-8.

Boehlje, M.D., Hofing, S.L. and Schroeder, R.C. (1999), Farming in the 21st Century, Department of Agricultural Economics, Purdue University, West Lafayette, IN.

Carmi, S. (1992), "The performance of an automated dairy management data-gathering system", in Ipema, A.H., Lippus, A.C., Metz, J.H.M., Rossing, W. (Eds), Proceedings of the International Symposium on Prospects for Automatic Milking, Wageningen, pp. 346-52.

DairyMetrics (2008), Dairy Records Management Systems, DairyMetrics, Raleigh, NC, January 27.

Dematawena, C.M.B. and Berger, P.J. (1997), "Effect of dystocia on yield, fertility, and cow losses and an economic evaluation of dystocia scores for Holsteins", Journal of Dairy Science, Vol. 80, pp. 754-61.

de Mol, R.M. (2000), Automated Detection of Oestrus and Mastitis in Dairy Cows, Wageningen University, Wageningen, p. 177.

de Vries, A. (2004), "Economics of delayed replacement when cow performance is seasonal", Journal of Dairy Science, Vol. 87, pp. 2947-58.

\section{Dairy business investment decisions}


AFR 70,1

Dhuyvetter, K.C., Kastens, T.L., Overton, M.W. and Smith, J.F. (2007), Cow culling decisions: costs or economic opportunity?, Proceedings of the Western Dairy Management Conference, Reno, NV, pp. 173-88.

Dijkhuizen, A.A., Renkema, J.A. and Stelwagen, J. (1991), "Modelling to support animal health control", Agricultural Economics, Vol. 5, pp. 263-77.

Dohoo, I.R. (1993), "Monitoring livestock health and production: service-epidemiology's last frontier?", Preventive Veterinary Medicine, Vol. 18, pp. 43-52.

Eleveld, B., Huirne, R.B.M., Dijkhuizen, A.A. and Overbeek, G. (1992), "Users in search of farm computer information technology: what do farmers want or need?", Farm Computer Technology in Search of Users: 4th International Congress for Computer Technology in Agriculture, Paris-Versailles, pp. 27-32.

FAPRI (2007), "FAPRI (Food and Agricultural Policy Research Institute) 2007 US and World Agricultural Outlook", in Missouri-Columbia., I.S.U.a.U.o. (Eds), Ames, IA, available at: www.fapri.iastate.edu/outlook/2007/text/OutlookPub2007.pdf

Ferguson, J.O., Galligan, D.T. and Thomsen, N. (1994), "Principal descriptors of body condition score in Holstein cows", Journal of Dairy Science, Vol. 77, pp. 2695-703.

Fourichon, C., Seegers, H. and Malher, X. (2000), "Effect of disease on reproduction in the dairy cow: a meta-analysis", Theriogenology, Vol. 53, pp. 1729-59.

Fox, D.G., Van Amburgh, M.E. and Tylutki, T.P. (1999), "Predicting requirements for growth, maturity, and body reserves in dairy cattle”, Journal of Dairy Science, Vol. 82, pp. 1968-77.

French, P.D. and Nebel, R.L. (2003a), Reproductive Program Cost Analysis.

French, P.D. and Nebel, R.L. (2003b), "The simulated cost of extended calving intervals in dairy herds and comparison of reproductive management programs", Journal of Dairy Science, Vol. 86, Supplement1, p. 54 (Abstract).

Friggens, N.C., Ingvartsen, K.L. and Emmans, G.C. (2004), "Prediction of body lipid change in pregnancy and lactation”, Journal of Dairy Science, Vol. 87, pp. 988-1000.

Galligan, D.T. (1999), "The economics of optimal health and productivity in the commercial dairy", Scientific and Technical Review of the Office International des Epizooties, Vol. 18, pp. 512-9.

Garnsworthy, P.C. (2007), "Body condition score in dairy cows: targets for production and fertility", in Garnsworthy, P.C. and Wiseman, J. (Eds), Recent Advances in Animal Nutrition 2006, University of Nottingham Press, Nottingham, pp. 61-86.

Gelb, E., Parker, C., Wagner, P. and Rosskopf, K. (2001), "Why is the ICT adoption rate by farmers still so slow?”, Proceedings ICAST, Vol. VI, Beijing, pp. 40-8.

Gelb, E.M. (1996), "The economic value of information in an information system", Sixth International Congress for Computer Technology in Agriculture, Wageningen, pp. 142-5.

Gould, B.W. (2007), Understanding Dairy Markets, University of Wisconsin-Madison, Madison, WI, available at: http://future.aae.wisc.edu/ (accessed 15 November).

Groenendaal, H., Galligan, D.T. and Mulder, H.A. (2004), "An economic spreadsheet model to determine optimal breeding and replacement decisions for dairy cattle", Journal of Dairy Science, Vol. 87, pp. 2146-57.

Grohn, Y.T., Rajala-Schultz, P.J., Allore, H.G., DeLorenzo, M.A., Hertl, J.A. and Galligan, D.T. (2003), "Optimizing replacement of dairy cows: modeling the effects of diseases", Preventive Veterinary Medicine, Vol. 61, pp. 27-43.

Guard, C.L. (1998), Costs of Common Diseases, Cornell University, Ithaca, NY, available at: www. ansci.umn.edu/dairy/toolbox/disease.xls (accessed 15 November 2007).

Hadley, G. (2003), "How does cow longevity affect your bottom line?", 2002 Midwest Dairy Herd Health Conference Proceedings, Middleton, WI. 
Huirne, R. (1990), "Basic concepts of computerised support for farm management decisions", European Review of Agricultural Economics, Vol. 17, pp. 69-84.

Huirne, R.B.M., Saatkamp, H.W. and Bergevoet, R.H.M. (2003), "Economic analysis of farm-level health problems in dairy cattle", Cattle Practice, Vol. 11, pp. 227-36.

Huirne, R.B.M., Harsh, S.B. and Dijkhuizen, A.A. (1997a), "Critical success factors and information needs on dairy farms: the farmer's opinion", Livestock Production Science, Vol. 48, pp. 229-38.

Huirne, R.B.M., Dijkhuizen, A.A., Van Beek, P. and Renkema, J.A. (1997b), "Dynamic programming to optimize treatment and replacement decisions", in Dijkhuizen, A.A. and Morris, R.S. (Eds), Animal Health Economics; Principles and Applications, Post Graduate Foundation in Veterinary Science, Sydney, pp. 85-97.

Humphry, R.W., Stott, A.W. and Gunn, G.J. (2005), "Modelling BVD at herd level compared with individual animal level”, Preventive Veterinary Medicine, Vol. 72, pp. 169-75.

Hutjens, M. and Aalseth, E. (2005), Caring for Transition Cows, Hoard's Dairyman, Fort Atkinson, WI.

Hyde, J. and Engel, P. (2002), "Investing in a robotic milking system: a Monte Carlo simulation analysis", Journal of Dairy Science, Vol. 85, pp. 2207-14.

Hyde, J., Stokes, J.R. and Engel, P.D. (2003), “Optimal investment in an automatic milking system: an application of real options", Agricultural Finance Review, Vol. 63, pp. 75-92.

Kertz, A.F., Reutzel, L.F., Barton, B.A. and Ely, R.L. (1997), "Body weight, body condition score, and wither height of prepartum Holstein cows and birth weight and sex of calves by parity: a database and summary", Journal of Dairy Science, Vol. 80, pp. 525-9.

Kinsel, M.L. (1998), An Economic Decision Tool for Dairy Cow Culling and Replacement, University of Minnesota, St Paul, MN.

Lee, J. and Bose, U. (2002), "Operational linkage between diverse dimensions of information technology investments and multifaceted aspects of a firm's economic performance", Journal of Information Technology, Vol. 17, pp. 119-31.

Lowman, B.G., Scott, N.A. and Somerville, S.H. (1976), Condition Scoring of Cattle, East of Scotland College of Agriculture, Edinburgh.

McInerney, J. (1996), “Old economics for new problems-Livestock disease: presidential address”, Journal of Agricultural Economics, Vol. 47, pp. 295-314.

Marsh, W. (1999), "The economics of animal health in farmed livestock at the herd level", Scientific and Technical Review of the Office International des Epizooties, Vol. 18, pp. 357-66.

Marsh, W.E., Galligan, D.T. and Chalupa, W. (1988), "Economics of recombinant bovine somatotropin use in individual dairy herds", Journal of Dairy Science, Vol. 71, pp. 2944-58.

NAHMS (2007), "Part I: Reference of dairy cattle health and management practices in the United States", USDA-APHIS-VS, CEAH, National Animal Health Monitoring System, Fort Collins, CO.

Norman, H.D., Wright, J.R., Kuhn, M.T., Hubbard, S.M. and Cole, J.B. (2007), "Genetic and environmental factors that affect gestation length", Journal of Dairy Science, Vol. 90, Supplement 1, p. 264.

NRC (2001), Nutrient Requirements of Dairy Cattle, 7th rev. ed., National Academy Press, Washington, DC.

Odening, M., Mußhoff, O. and Balmann, A. (2005), "Investment decisions in hog finishing: an application of the real options approach”, Agricultural Economics, Vol. 32, pp. 47-60.
Dairy business investment decisions 
AFR 70,1

Oltenacu, P.A., Rounsaville, T.R., Milligan, R.A.and Foote, R.H. (1981), "Systems analysis for designing reproductive management programs to increase production and profit in dairy herds", Journal of Dairy Science, Vol. 64, pp. 2096-104.

Pecsok, S.R., McGilliard, M.L. and Nebel, R.L. (1994), "Conception rates. 1. Derivation and estimates for effects of estrus detection on cow profitability”, Journal of Dairy Science, Vol. 77, pp. 3008-15.

Perry, B.D. and Randolph, T.F. (1999), "Improving the assessment of the economic impact of parasitic diseases and of their control in production animals", Veternary Paristology, Vol. 84, pp. 145-68.

Rajala-Schultz, P.J. and Gröhn, Y.T. (1999), "Culling of dairy cows. Part I. Effects of diseases on culling in Finnish Ayrshire cows", Preventive Veterinary Medicine, Vol. 41, pp. 195-208.

Rushton, J., Thornton, P.K. and Otte, M.J. (1999), "Methods of economic impact assessment", Scientific and Technical Review of the Office International des Epizooties, Vol. 18, pp. 315-42.

Ryan, S.D. and Harrison, D. (2000), "Considering social subsystem costs and benefits in information technology investment decisions: a view from the field on anticipated payoffs", Journal of Management Information Systems, Vol. 16, pp. 11-40.

Seavert, C., Hinman, H. and Klonsky, K. (2006), "A crop profitability analysis for long-term crop investments”, Agricultural Finance Review, Vol. 66, p. 125.

Silva de Rio, N., Stewart, S., Rapnicki, P., Chang, Y.M. and Fricke, P.M. (2005), "An observational analysis of twin births, calf sex ratio, and calf mortality in Holstein dairy cattle", Journal of Dairy Science, Vol. 88, Supplement 1, p. 298.

Skidmore, A.L. (1990), Development of a Simulation Model to Evaluate Effectiveness of Dairy Herd Management, Cornell University, Ithaca, NY, p. 236.

Sorensen, J.T., Kristensen, E.S. and Thysen, I. (1992), "A stochastic model simulating the dairy herd on a PC", Agricultural Systems, Vol. 39, pp. 177-200.

Spilke, J. and Fahr, R. (2003), "Decision support under the conditions of automatic milking systems using mixed linear models as part of a precision dairy farming concept”, EFITA 2003 Conference, Debrecen, pp. 780-5.

St-Pierre, N.R. (1999), "Special Circular 163-99: a model for projecting animal numbers in a closed herd", The Ohio State University, Columbus, $\mathrm{OH}$.

Streeter, D.H. and Hornbaker, R.H. (1993), "Value of information systems: Alternative viewpoints and illustrations", in Farm Level Information Systems, Wageningen Academy Publishers, Wageningen, pp. 283-93.

USDA-AIPL (2006), Genetic and Phenotypic Trends, available at: http:/aipl.arsusda.gov/ (accessed 15 November 2007).

USDA-NASS (2007), Agricultural Prices Summary, available at: http://usda.mannlib.cornell.edu/ MannUsda/viewDocumentInfo.do?documentID=1003 (accessed 15 November).

van Arendonk, J.A.M. (1985), "A model to estimate the performance, revenues and costs of dairy cows under different production and price situations", Agriculture System, Vol. 16, pp. 157-89.

van Asseldonk, M.A.P.M. (1999), "Economic evaluation of information technology applications on dairy farms", $\mathrm{PhD}$ dissertation, Wageningen University, Wageningen, p. 123.

van Asseldonk, M.A.P.M., Jalvingh, A.W., Huirne, R.B.M. and Dijkhuizen, A.A. (1999), "Potential economic benefits from changes in management via information technology applications on Dutch dairy farms: a simulation study", Livestock Production Science, Vol. 60, pp. 33-44.

Verstegen, J.A.A.M., Huirne, R.B.M., Dijkhuizen, A.A. and Kleijnen, J.P.C. (1995), "Economic value of management information systems in agriculture: a review of evaluation approaches", Computers and Electronics in Agriculture, Vol. 13, pp. 273-88. 
Winston, W.L. (2001), Simulation Modeling Using @Risk: Updated for Version 4, Duxbury Press, Pacific Grove, CA.

\section{About the authors}

J.M. Bewley is affiliated with the Department of Animal Sciences, Purdue University, West Lafayette, Indiana, USA. J.M. Bewley is the corresponding author and can be contacted at: jbewley@uky.edu

M.D. Boehlje and A.W. Gray are affiliated with the Department of Agricultural Economics, Purdue University, West Lafayette, Indiana, USA.

H. Hogeveen is affiliated with the Faculty Veterinary Medicine, Utrecht University, Utrecht, The Netherlands.

S.J. Kenyon is affiliated with the Department of Veterinary Clinical Sciences, Purdue University, West Lafayette, Indiana, USA.

S.D. Eicher is affiliated with the Livestock Behavior Research Unit, Agricultural Research Service, USDA, West Lafayette, Indiana, USA.

M.M. Schutz is affiliated with the Department of Animal Sciences, Purdue University, West Lafayette, Indiana, USA.
Dairy business investment decisions

To purchase reprints of this article please e-mail: reprints@emeraldinsight.com Or visit our web site for further details: www.emeraldinsight.com/reprints 